1935

\title{
Acute suppurative otitis media
}

Harold F. Hoefer

University of Nebraska Medical Center

This manuscript is historical in nature and may not reflect current medical research and practice. Search PubMed for current research.

Follow this and additional works at: https://digitalcommons.unmc.edu/mdtheses

Part of the Medical Education Commons

\section{Recommended Citation}

Hoefer, Harold F., "Acute suppurative otitis media" (1935). MD Theses. 391.

https://digitalcommons.unmc.edu/mdtheses/391

This Thesis is brought to you for free and open access by the Special Collections at DigitalCommons@UNMC. It has been accepted for inclusion in MD Theses by an authorized administrator of DigitalCommons@UNMC. For more information, please contact digitalcommons@unmc.edu. 
ACUTE SUPPURATIVE OTITIS MEDIA

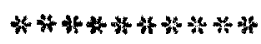

SENIOR THESIS

$-1935-$

UNIVERSITY OF NEBRASKA

COLLEGE OF MEDICINE

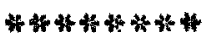

BY

-HAROLD $P$. HOEFER- 
TABLE OF CONTENIS

\author{
INTRODUCTION \\ HISTORY ANATOHY \\ ANATOMY \\ ETIOLOGY \\ PATHOLOGY \\ ZYMPTOMS AND SIGNS
}

DIAGNOSIS

COMPLICATIONS

B IBL IOGRAPHY
PAGES

$7-8$

$9-13$

$13-24$

$25-33$

$34-35$

$36-59$

$60-65$

$66-68$

$69-84$

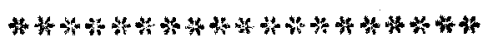


Otitis Media Suppurativa Acuta is an acute inflametion of the mucous membrane of the tympanum, and usually also of that of the eustachian tube and mastoid cells.

The term "Acute Suppurative otitis media", as a definite entity, fails in the great majority of the cases to desoribe adequately from an anatomical and pathological point of view, coincident involvement of structures adjacent to and continuous with the tympanum, namely the mastoid and eustachian tube.

In contrast to the anatomical and pathological point of view, however, acute suppurative otitia media does describe a quite definite clinical entity, and as such, it will be discussed in this thesis.

It should be understood that the "middle ear" is to include the whole of the midale ear cleft, which starts in the nasopharynx, runs up the eustachian tube, enters the middle ear or tympanum proper, invades the upper regions of that cavity which is known as the attic, and from there leads upward through a small tunnel or aditus into the mastoid antrum and air cells; and one continuous membrane lining all structures. With this picture in mind, the clincial manifestations will be more easily comprehended.

The complicated structure of the temporal bone has served through the years to baffle investigators in the true understanding of acute suppurative otitis media, and only in recent years, through investigators in anatomy, physiology, pathology and surgery, served to clear up the hidden mysteries within the temporal bone. 


\section{-INTRODUCTION-(2)}

The complicated structure of the bone on the one hand, and the inclusion of the middle and inner ear in this body cavity on the other, mean many dangers for the patient with ear disease.

So it is with deep concern that we attempt to avoid these, by means of a more clear understanding of the patient, correct interpretation of signs and symptoms and the instituting of the proper treatment.

This problem will be discussed in the following manner: (1) Anatomy, (2) Etiology, (3) Pathology, (4) Symptoms and Signs, (5) Diagnosis, (6) Complications. 
-ANATOMY-

(3) The early history of the anatomy of the ear dates back as far as 400-500 B. C. when the Greeks recognized the presence of the auditory (Eustachian) tube, and believed the davity of the ear was filled with air. It was Hippocrates who was first to recognize the importance of the drum membrane, al though Galen later ascribed to it a role of minor importance.

It was not until $1500 \mathrm{~A}$. D. that the parts of the middle ear were discovered, but there is some disagreement as to whom.

Eustachius (1510-1574) gave much to otology. He was the first to give a detailed study of the temporal bone. Although not the first to observe the tube which bears his name, but he described it accurately and realized its significane.

Vesalius (1514-1564) is accredited with the first descripton of the middle ear cavity, antrum and pneumatic cells. Like Eustachius, Vesalius recorded his observations in the form of beautiful engravings. Since his work never suffered a period of oblivion as did that of Eustachius, Vesalius goes down in history as the first to publish illustrations of the middle ear and its ossicles. In his original Latin text he states: We surm mise that neither Galen nor any other before him had observed these, (small bones in the ear) from the fact that no reference is made to them anywhere. In the temporal bone there is hollowed out a large and rather irregular cavity which gives rise tofour openings. Some areas in the cavity are flat and smooth; some are like soft pumice and a sponge full of holes of varying size and no two alike. He then goes on to describe the small bones, com- 
paring the incus to an anvil or a molar tooth, and describing the second little bone (malleus) as varying considerably from the incus, and being fastened upon a membrane. He then states: The opening of the cavityof the antrum hollowed out in the temporal bone which pertains to the ear is covered in the part nearest the diameter of the cavity by a very delicate and almost transparent little membrane in the manner in which we say a vase is closed by its bottom (base). This little bone (Malleus) is flattened obliquely upon this little membrane, and stretches cross-wise and inward, like a tambour with one string and another heavier stretched over the membrane or ox-hide. That the bone may be fastened more firmly, however, it has a long thin process by means of which it is fastened upon the membrane along its breadth. One may compare this process to the part of the femur, which reaches from its processes, called the trochanters, to the lower shaft. Indeed if you imagined the lower shaft of the femur cut off, the entire bone (malleus) will be favorably compared to the shortened femur. For just as the femur at the side of its neck has two processes, so this little bone has little processes in the same place, by means of which it is fastened more firmly upon its membrane. Then just as the neck of the femur lies obliquely toward the interior of the body, at the curve of the hip bone and comes to a completely rounded head, so also this little bone tends inwardly from the membrane and comes to a rounded head, which is smooth and not uneven, and is connected with the upper part of the other little bone (Incus), which we compared to a 
molar tooth or an anvil, but an exceedingly small anvil considering the size of the hammer.

Fallopius (1523-1562) observed that the mastoid process was absent in the new born and gradually increases in size with the process of growth. He recognized the communication of the mastoid cells with the middle ear cavity. He believed pus in the middle ear to be an exudate from the brain as did Hippocrates. Fabricus ab Aquapendents (1537-1619) a pupil of Fallopius, observed that the middle ear cavity of the new born is filled with mucous. This was undoubtedly what we now know to be me senchyme.

With the approach of the 17 th century the interest in anatomical investigation was gradual ly disseminating from I taly. Almost like a bibical geneological chapter, runs the history of each great anatomist teaching his successor. As Vesalius trained Fallopius, so Fallopius trained Fabricus.

From Italy the center of learning was now definitely spreading north to France. The most important French contributor of the time was du Verney (1648-1730). He states: the ear is composed of an external and internal part. The internal part consists of a "cavitas prima" and a "cavitas secunda". The cavitas prima contains five important parts to be noted. (1) Two meati, one which leads to the palate, one which leads to the mastoid; (2) Two windows; (3) Four ossicles, malleus, incus, stapes, and the last he simply refers to as "quartum". This is quite evidentIy the lenticular process of the stapes. It is well known that in the infant this is separate. In the adult the delicate attach- 
ment to the incus is often less durable than the incudo-stapedial joint, so that it might easily be mistaken for a separate bone, especially in suppurating ears.

Valsalva (1666-1723) divided the ear into three parts, exactly as is done by modern investigators. In describing the tympanic membrane, he still held to the idea of the older anatomists, that the membrane was derived from the dura, although he recognized that externally, it was covered with cutis.

Cotugno (1736-1822) made many contributions in regard to sound. He is the discoverer of the endolymphatic fluid. Alphonse Corti (1851) gave the first detailed description of the sensory end of hearing. Corti because of advancing disease, probably arthritis deformans, was forced to retire. How great the loss of science because of his inability to continue his investigations can never be estimated.

From this time to the present, the number of important investigators of the anatomy of the ear multiplied rapidly. Among these is a name familiar to all biologists as that of the originator of the term "Protoplasm". He established the fact that this is practically indentical in plants and animals. Having made these discoveries, he turned his attention to study the nerve cell and gave important contributions to the knowledge of the nerve endings in the ear.

Dorothy Wolff states: "Enumeration of names already familiar to the reader is but dull tribute to the honor of the many modern investigators who have increased our knowledge concerning this complicated organ!. Its "minute and intricate struc- 
ture", continues to attract not only the investigators of anatomy, but those of physiology, pathology and surgery.

(47) The present concept of the anatomy of the middle ear is a narrow cleft-like space in the temporal bone. Anterior1y it communicates with the nasopharynx by means of a passage called the auditory (Eustachian) tube. The part of the space that lies above the level of the tympanic membrane is called the epitympanic recess (attic). Posteriorly the recess communicates by means of an opening, called the aditus, with the tympanic antrum, and through that with the mastoid air-cells. For convenience, the term "middle ear" is sometimes applied to the tympanic cavity.

The middle-ear cleft, which includes the auditory (Eustachian) tube, tympanic cavity, attic, aditus, antrum, and air-cells, is developed from the first visceral pouch of the embryo. It is an air-containing space formed by the upward and backward growth into the temporal bone of a hollow bud of mucosa from the nasopharynx. In early foetal iffe this hollow bud barely reaches the tympanic membrane, while the upper and posterior portions of the cleft are still filled with foetal connective tissue. Later on, the bud of mucous membrane expands backward so as to line the tympanic cavity, aditus, tympanic antrum and mastoid air-cells. During this process the tympanic ossicles and the chorda tympani nerve, to be mentioned later, receive a covering of mucosa. It will thus be seen that the formation of the miadle ear cleft is comparable in its development with that of the maxillary and frontal sinuses. In the same way the pathology of 
-ANATOMY-(6)

the middle ear cleft corresponds to that of the paranasal sinuses. The Auditory (Eustachian) Tube, which is funnel-shaped and about $35 \mathrm{~mm}$. (one inch and a half) in length, runs upwards, laterally, and backwards from its anterior and lower opening in the side wall of the nasopharynx, just behind the posterior end of the inferior concha or turbinal. The close anatomical relationship of the tube to the nose and pharynx makes it liable to participate in catarrhal affections of those regions, especialIy in infants, in whom the tube is shorter, wider, and more horizontal than in adults. The tube has two parts: an anterior or cartilaginous which forms two-thirds of its length, and a posterior or bony portion. The narrowest part, or isthmus, is situated at the point where the two portions meet. The upper and medial walls of the anterior portion of the tube are formed by a plate of cartilage which appears hook-like in vertical coronal sections. The lateral wall of the tube is membranous. In the resting state the lateral and medial walls lie in appostion. The fibres of origin of the dilator tubae (tensor palati) muscle are attached to the lateral or membranous wall of the tube in such a way that, when this muscle contracts during the act of swallowing, the tube is opened and equality of air-pressure on both sides of the tympanic membrane is maintained.

The bony portion of the tube should be regarded as the anterior part of the tympanic cavity. It lies between the internal carotid artery which is situated on its medial and the mandibular joint, on its lateral side. The tensor tympani muscle 


\section{-ANATOMY $-(7)$}

Iies in a bony canal above it. On vertical coronal section the tube presents an almost quadrilateral lumen. Eustachian curettes should be modelled accordingly.

The auditory tube is lined with mueous membrane covered with ciliated columnar epithelium. The submucous tissue of the cartilaginous part contains numerous mucous glands which open into the lumen. Adenoid tissue is also present in the pharyngeal portion, and constitutes the "tubal tonsil".

The Tympanic Cavity measures about $15 \mathrm{~mm}$. (half an inch) from above downwards and from behind forwards, but it is very narrow from side to side. It is wider above, in the region of the attic, than below, and is deeper behind than in front. It is usually described as consisting of two parts: the tympanic cavity proper, which lies on the medial side of the tympanic membrane, and the epitympanic recess, or attic, above the level of the drumhead. A small narrow portion of the cavity, lying below the level of the drumhead, was formerly known as the hypotympanic cavity, or celler.

The tympanic cavity may be described as a six-sided box. The roof of the box, which is often very thin is formed by the tegmen, tympani, a plate of bone which passes laterally from the petrous to articulate, and later fuse, with the squama. Above the roof lies the dura mater of the middle fossa of the skull with the temporal lobe of the brain.

The floor of the box separates the cavity from the bulb of the internal jugular vein and the carotid artery. Here again the bony partition may be exceedingly thin. In front, the 
-ANATOMY-(8)

tympanic floor slopes upwards into the anterior wall, which has two openings; the lower one is the tympanic orifice of the auditory (Eustachian) tube, while above this lies the canal for the tensor tympani muscle.

The posterior wall, in its upper part shows a somewhat triangular opening--the aditus, which connects the epitympanic recess (attic) with the tympanic antrum. Just below this opening on the posterior wall there is a bony projection (pyramid) which gives exit to the tendon of the stapedium muscle. The descending part of the facial nerve courses downwards in close relation to the posterior wall. On the medial side of the pyramid and bony covering of the facial nerve there is a recess named the sinus tympani, which lies in close relation to the medial or labyrinthine wall of the tympanum and the ampulla of the posterior semicircular canal. The sinus tympani corresponds to the tympanic bulla of lower mammals.

The lateral wall of the tympanic cavity is formed mainIy by the drumhead. Above this, however, there is the lateral wall of the attic, formed by the horizontal part of the squama. The medial wall of the tympanum is a party-wall, i.e., it is also the lateral wall of the internal ear or labyrinth. The medial tympanic wall shows two openings; postero-superiorly lies the fenestra vestibuli (oval window), while below this there is the niche leading to the fenestra cachleae (round window). Infection may pass from the tympanum to the labyrinth through the oval or round windows, or through the bony prominence of the lateral semi- 
-ANATOHY- (9)

circular canal to be mentioned later. In front of and between these fenestrae lies the promontory $\rightarrow$ the bony covering of the basal coil of the cochlea. Above the fenestra vestibuli runs the horizontal portion of the facial nerve enclosed in a thin covering of bone. On the extreme anterior and superior part of the medial wall there is a hollow bony process (processus cochleariformis) which contains the tendon of the tensor tympani muscle. The upper part of the tympanic cavity (attic) is the widest portion. It is divided into two sections (lateral and medial) by the head of the malleus, the body of the incus and the superior ligament.

The tympanic aditus (iter ad antrum) is usually triangular on vertical transverse section, and is the opening from the epitympanic recess into the antrum. On the medial wall and floor of the aditus is situated the white prominence produced by the bony wall of the lateral semicircular canal. The floor of the aditus is higher than that of the tympanic antrum. Strictly speaking, the tympanic cavity contains only air as the three ossicles (malleus, incus, and stapes), the two muscles (the tensor tympani and stapedius), and the chorda tympani nerve are covered by the lining membrane and therefore lie outside the cavity-of. the intestinal tract and the peritoneal cavity

Tympanic Ossicles.--The malleus consists of a head, neck, short process, and handle. The handle is firmly attached to the drumhead. The incus is shaped like a premolar tooth, and consists of a body, which articulates with the head of the malleus, a short crus fixed to the floor of the aditus, and a long crus 
-ANATONY-(10)

which descends into the main portion of the tympanic cavity to articulate with the head of the stapes. The stapes itself close1y resembles the stirrup from which it takes its name. It is made up of a head, neck, an anterior and posterior crus, and a footm plate. An Annular ligament joins the footplate to the margins of the oval window.

Tympanic Muscles--The tensor tympani arises outside the tympanic cavity, and its tendon, after leaving the apex of the processus cochleariformis, passes laterally at right angle across the tympanic cavity to be attached to the handle of the malleus. The muscle is supplied by the motor division of the trigeminus, through the otic ganglion. Its action is to draw inward the tympanic membrane and ossicular chain and consequently, to raise the intralabyrinthine pressure. The tendon of the stapedius muscle, after emerging from the pyramid, is inserted into the neck of the stapes. The muscle is supplied by the 7th nerve, and, when it contracts, tilts outwards the anterior end of the stapedial footplate and lowers the intralabyrinthine pressure. Contraction of the tensor tympani interferes with the hearing of low tones, whereas contraction of its antagonist, the stapedius, tends to improve the hearing. When we make an effort to hear, it is probably the stapedius that is brought into play.

Tympanic Ligaments,--The anterior and posterior ligaments of the malleus surround the neck of that ossicle, and together form the axis ligament which is attached anteriorly and posteriorly to the ends of the notch of Rivinus. From the head of the malleus and body of the incus a double layer of mucosa 
passes upwards to the roof of the tympanic cavity (superior ligament). The movements of the malleus and incus take place through an axis which passes through the neck of the malleus and body and short crus of the incus. When the portions of the ossicles situated below this axis move medially, the upper portions move laterally, and vice versa.

Vessels and Nerves of the Tympanic Cavity....The tympanic cavity is richly supplied by branches from adjacent arteries. The veins of the tympanic cavity enter the pterygoid plexus, the riddle meningeal veins, the jugular bulb, the superior petrosal sinus and carotid venous plexus. The lymphaties drain into the retropharyngeal and parotid lymph glanas. The sensory nervesupply is in the form of a plexus which lies on the medial wall of the tympanum, and is formed by the tympanic branch of the glossopharyngeal (Jacobsen's nerve), a branch from the geniculate gangIion on the facial, the small deep petrosal from the carotid plexus and the small superficial petrosal to the otic ganglion. The Chorda tympani nerve, enclosed in a fold of mucous membrane, traverses the cavity from before backwards, and passes between the handle of the malleus and the long crus of the incus.

The facial nerve runs in three different directions during its course within the temporal bone. At first it passes laterally in the internal auditory meatus, and then curves slightly upwards over the labyrinth until it comes to the anterior part of the medial wall of the tympanum near its roof. Here it bends backwards at a right angle and passes almost horizontally, immediately 
above the oval window. When it reaches the aditus it turns downwards and continues vertically until it emerges from the stylom mastoid foramen.

The Mastoid Temporal Bone lies below and behind the squama, and behind and lateral to the petrous. From its lower part in the adult there juts downwards the mastoid process. This process is absent at birth, and is small in early childhood. The mastoid temporal may consist almost entirely of air-cells with thin bony walls (cellular or pneumatic mastoid), or it may be composed mainly of sclerotic or diploetic bone (acellular or dense mastoid). The tympanic antrum is always present from birth onwards. Cheatle pointed out that in the infant, in addition to the tympanic antrum, there are present only a few air-cells, which are situated in the lateral wall of the antral cavity. In the great majority of cases(80 percent) the mastoid becomes hollowed out by air-cells, which spread outwards, backwards and downwards from the antrum. In the remaining 20 percent of cases, however, the normal pneumatization fails to occur, so that the mastoid temporal remains dense or acellular--the so-called "persistent infantile" type. Recently Wittmaack has stated that the dense type of mastoid is really a pathological one and is due to inm fantile otitis media which interferes with the normal absorption of the mastoid diploe and the consequent pneumatization of the bone. Albrecht, however, disagrees and holds that pneumatization depends on the energy of the invading epithelium and the resistance of the surrounding tissue quite apart from the presence or absence of otitis media. As a rule in light and soft-boned skulls 
the air-cells of the mastoid are numerous and well developed, while in thicker and harder skulls the cells are small and scanty.

In the infant the stylomastoid foramen lies almost on the surface, and for this reason it is advisable not to prolong the incision for the mastoid operation unduly in a downward direction, as otherwise the facial nerve may be cut just after it emerges from the foramen. Further, in the infant, the antrum lies at a higher level than in the adult and is very superficial, being covered only by a thin lamella of bone which descends from the lower portion of the squamous temporal. Later on, as the mastoid process develops, the antrum comes to occupy a somewhat lower level. The roof of the tympanic antrum is merely the continuation backward of the tegman tympani. The floor and medial wall of the antrum are formed by the petromastoid bone. On the medial wall of the tympanic antrum there is a series of small veins--the remains of an important foetal vein-which pass through the fossa subarcuata, beneath the dome of the superior canal, to reach the posterior surface of the petrous pyramid, and there, to open into the superior petrosal sinus. Infection may pass along this route and give rise to meningitis. The air-cells connected with the middle ear cleft vary considerably in size and number in different persons. They are all lined by flattened epithelium and communicate with the antrum, aditus or tympanum. The mastoid cells form two groups--the squamomastoid and the petromastoid. The first group includes the cells in the anterior, lateral and inferior parts of the process, the latter those in the posterior, medial and superior portions. The 
antrum itself is formed from both groups and sometimes show a ridge, indicating the line of division. The air-cells may extend in various directions: (1) Those constantly present are the cells in the lateral wall of the antrum, which, as has been said already, may come to occupy the whole lateral portion of the mastold process and reach the tip, where a large cell is of ten present. Some of these air-cells usually extend into the posterior wall of the bony meatus in its upper part, forming the so-called "border" air-cells. In cases of middle ear suppuration, inflammation in these cells may lead to sagging downwards of the lining membrane of the external meatus at its medial and upper part. Occasionally air-cells extend into the posterior root of the zygoma and upwards into the squama. Infection of these cells may give rise to the "zygomatic" type of mastoiditis with swelling above and in front of the auricle. The above two groups belong to the squamomastoid portion. (3) Cells may extend medially, to surround the posterior vertical semicircular canal. These cells have been named by Neumann the epibulbar or sublabyrinthine cells. (4) Cells may reach backwards to the dense bone which forms the wall of the sigmoid groove, and may extend superficial to the sinus as far as the occipital bone (marginal cells). (5) Air-cells may extend upwards and backwards superficial to the upper knee of the sigmoid sinus-mthe so-called "posterior superior" or "petrosal-angle" cells. Groups (3), (4), and (5) belong to the petromastoid division. (6) From the tubal portion of the tympanic cavity air-cells may extend into the surrounding bone and reach almost to the apex of the petrous pyramid. 
Recent work on the anatomy of the tympanum and mastoid reveals the following:

Meltzer (21) after observation continued over a period of twelve years and basing his conclusions on many hundreds of dissections and findings at operation on the mastoid process, contends that mastoid cells when present, are arranged in a systematic manner, dependent primarily on the course and position of the lateral sinus. This vessel, in its relationship to the cortex of the squama posterosuperiorly and to the cortex of the mastoid process laterally and posteriorly, influences the cell arrangement. Whether the cells are large, snall, pneumatic, diploic or of mixed type, their general arrangement will be systematic according to the relationship of the lateral sinus to structures mentionea.

Concerning the mastoid tip cells Wittmaach (2I) has observed an off-shoot of the sub-epithelial tissue filling the iniddle ear at birth, extending from the posterior--inferior angle of the hypotympanum back under the facial canal and down to the mastoid tip. He believes this process was concerned in the pneum matization of the tip entirely separate from the usual spread of pneumatization from the tympanic antrum. Almour (20) has demonstrated a definite tract of cells from the hypotympanum under the facial canal to the tip cells in twenty-four consecutive well pneumatized adult temporal bones. This demonstration was made by blocking off the antrum with clay and injecting water into the middle ear; it will enter the tip cells but not the other mastoid cells. Also a fine wire can be passed into a cavity at the junction 
of the posterior and inferior walls of the tympanus at a point directly below the round window. If the mastoid tip is now dissected, the tip of the probe comes into view. on the basis of these observations Almour suggests the possibility of a pneumatized tip cell in an otherwise sclerotic mastoid, he also offers his observations as an explanation for the frequent finding of an isolated empyema of the tip with intact cells through the remainder of the mastoid. Kopetzky (I) blieves that Almour's experiments and observations have clarified the mechanics of invasion for the clinical picture and operative findings. He also states that this tract corresponds roughly to the tract termed "retro facial" by Meltzer. 
The etiology of acute suppurative otitis media not only turns our attention to the propholactic aspect of the disease, but of ten times serves as a guide to interpreting signs and symptoms and the specific type of treatment to be pursued. Suppuration of the middle ear presupposes bacterial invasion, and may result from any inflamatory condition of the upper air passages by way of the eustachian tube; hence of the direct causes of the middle ear suppuration, the common cold is by far the most frequent; although, it is a very common sequela of the exanthemata especially measles and scarlet fever, and occurs frequently in influenza, whooping cough, diphtheria, pneumonia, parotiditis, small pox, typhoid fever, tuberculosis and syphilis. (48), (45), (67), (47), (49).

In children it may be caused by irritation of the mucous membranes from teething or from carious teeth. It frequently follows vigorous syringing of the nose and is frequently seen as a complication from operations on the nasal cavities and naso-pharynx. Packing the nose, or plugging the naso-pharynx in severe cases of epistaxis may give rise to acute middle ear suppuration, especially if the plugs are left in for more than twenty-four hours. Otitis media may also result from bathing in the sea or public baths; infection passing by way of the eustachian tube, unless an old damaged ear allows access by way of the external meatus. The micro-organisms of public baths and the sea are blamed, but no doubt the upper respiratory passages of the victim supply the lurking streptococcus in many cases. Bathers 


\section{-ETIOLOGY-(2)}

who get water into the nose or naso-pharynx should not blow the nose violently, but should allow the water to run out. violent blowing of the nose acts like Valsalva's inflation and drives the fluid which may be septic, into the middle ear cleft. This also holds true in infections of the upper respiratory tract with pus in the region of the naso-pharynx, as violent blowing of the nose or even from swallowing while lying on the side, increases the probability of an accidental infection of the ear. A second route of infection in cases of otitis media is by way of the external meatus following injuries of the drumhead. One possibility of this has previously been mentioned. Fractures of the skull envolving the temporal bone are sometimes followed by otitis media-the infection coming either by way of the ruptured drumhead or through the eustachian tube. In rare cases otitis media may follow auppuration in the labyrinth resulting from epidemic cerebrospinal meningitis. In this case the middle ear is infected by the purulent exudate from the labyrinth invading the middle ear through the oval or round window. Lastly must be considered the spread of infection and the part played by the blood and lymphatics. These possibilities are brought forth as apart of the picture of acute suppurative otitis media occurring in conjunction with severe infectious diseases, tuberculosis and syphilis. And according to wirth 68 some of the inm fections of the upper respiratory tract; as he believes the spread of infection from the surface of the nasal mucous membrane reaches the midale ear in the same manner as erysipelas infection spreads in the skin. (45), (47), (48), (49). 
Otitis media is very frequent in infancy. In the new born it isn't uncommon from forcing of liquor amnii or meconium into the middle ear during parturition. Many of these cases of otitis are sterile and are merely the reaction against foreign body irritation. According to Preysing those that are infected are generally pneumococci. (49)

According (32) to various statistics the maximum of frequency lies in the second to fourth months. The cause of the frequency of otitis media at this age is to be found in the anatomical structure of the ear passages in infancy. Here should be mentioned the presence of mucous tissue and liquid mucous in the middle ear, which is an excellent culture medium for penetrating bacteria, the presence of connective tissue strands and mucous membrane septa in the middle ear, whereby on the one hand, the formation of an empyema under pressure is delayed, but on the other hand, the free outflow of the pus is hindered all the more because granulations form easily on the basis of these tissue strands. Here belong further the insufficient cormunication of the antrum with the middle ear, whereby the continuation of suppuration in the antrum, when the middle ear hasalready healed is made possible, and further the short and wide eustachian tube which on the one hand, furthers the penetration of infectious material from the pharynx, by swallowing, vomiting or swallowing the wrong way, so frequent in infants, but on the other hand makes possible the draining of the pus from the middle ear into the pharynx. If one considers further that the infant is in 
a horizontal position most of the time, whereby the middle ear lies under the pharynx, and that further the epipharynx is not closed off from the mesopharynx as securely as in the adult, because of the relatively short soft palate, and if one considers finally, the frequency of inflamatory processes in the pharynx. of the infant, the frequency of otitis in infancy is completely understandable.

Costen (42) in a few of these caseshas cultured foul smelling secretions from an acute otitis of only a few days duration and found colon bacillus or Bacillus proteus; thus pointing out the possiblity of regurgitated stomach contents reaching the middle ear.

From infancy to childhood brings us to the time when enlargement of the respiratory tonsil leads to the condition called adenoids, which with the mechanical production of stasis of infectious material in the eustachian tube, lead the list of predisposing factors to acute otitis media. Now and during the earlier days of school life this trouble in the naso-pharynx receives much blame for damage in the middle ear. Fortunately as the years pass by, the length of the eustachian tube increases and the tympanic cavity lies further away from the naso-pharynx, the naso-pharynx itself becoming more spacious. Such changes are favorable to the auditory organ, until we find the adult not so much a victim of recurring middle ear mischief as a sufferer from less frequent but more definitely established attacks. (42) (45)

The nature of the invading organism ranks third as a predisposing factor, the first of which is certainly the invasive 
-ETIOLOGY $-(5)$

class, such as streptococcus and pneumococcus in scarlet fever and pneumonia; second, activation of any of the bacteria already present in the naso-pharynx and mouth is a constant hazard, dependent on daily habits, nourishment, economio condition, as follows; chilling of body surface; lack of food and lowering of resistance that goes with half starvation; and, a thing we encounter not infrequently, the production of otitis media after a dose of vaccine or immunizing antigen. Certain of these have shown themselves to be of value, but the hazard lies in giving it when there is an acute condition in the nasal or throat mucosa. (42)

Heredity dispostion to otitis media has been worked out quite carefully by Baselin (57), and he presents three geneological tables to illustrate the importance of hereditary disposition. In his opinion the theories which attribute to the local hereditary constitution of the mucosa a role in the pathogenuses of the otitis media appear well founded. He believes that the geneological tables show the indications forprognosis and therapy of otitis media, which a careful family anamnesis may contribute. Forster (45) and Turner (47) also believe heredity to play a predominant role. Forster also bringing out the importance of congenital defects and atrophic disease of the nose and accessory sinuses. (67) Obstructed nasal breathing from whatever cause is injurious to the middle ear. Hypertrophied and diseased inferior turbinals, by obstructing the chief channel for the entrance of air, often show a marked tendancy to aggravate midale ear inflamations. 
Cystic and polypoid middle turbinals tend also to produce the same result. A more or less completely deflected septum, interfering as it does with nasal respiration, likewise aggravates the symptoms of middle ear inflamations. Tumors, whether malignent or otherwise, acting directly as a result of obstruction or indirectly by lowering the vitality, must also be considered.

(43) Repeated examinations of the oropharynx and nasopharynx in healthy individuals revel the presence of various forms of bacteria, harmless and otherwige; the middle ear, being in practically direct communication with these, would lead one to believe it is never free from bacteria and this has been proven by investigations carried out by Hasslauer.

"When the mucous membrane lining is normal these germs are not present in sufficient quantities nor are they sufficiently active to cause any disturbance. If however, the circulation is disturbed by some temporary congestion of mucous membrane within the middle esr, such as exposure to cold,chilling of body, etc., it renders the tissues more vulnerable and the organisms proliferate giving rise to characteristic symptoms."

(67) Changes in the tissues which enter into the makeup of the middle ear, are undoubtedly directly influenced by dearrangements in the character and normal functions of the blood vessels and lymphatics. Systemic diseases, such as diabetes, gout and rheumatism, and those resulting from the improper use of medications, intoxicants or narcotics, by acting upon the vascular system in general, also affect to a marked degree, the tissues 


\section{-ETIOLOGY-(7)}

of the tympanic cavity. Here also might be mentioned the role played by allergy in the niddle ear, of which we know very little at the present time.

Incidentally various other factors tend to influence and aggravate the purulent process in the midale ear, such as bad habits, excessive alcohol, neuroses and the presence of general debilitating diseases, as, for instance diabetes.

Of the more chronic forms of infection those involving the accessory sinuses of the nose are quite prolific in the causation of purulent otitis media. The author (67) has repeatedly observed cases of violent purulent otitis media that could be directly traced to the forced induction of the discharges from the accessory sinuses through the Eustachian tube into the tympanic cavity.

Tuberculosis and syphilis on account of their frequent occurrence warrant special mention. The manifestations of tuberculosis are always those of ulceration and destruction of the membrana tympani and also of the intra tympanic structures. The route by which tuberculosis reaches the iniddle ear and mastoid has aroused endless discussion. (34) The infection may, and probably does, enter the cavity through the Eustachian tube with comparative frequency, due to infected sputum and in the case of little children by the same route on vomiting. More rarely by the hematogenous route and lymphatics which occurs as a result of similar disease in the vascular systems. Open perforation and direct infection by an infected finger or instrument offers another possibility. Despons (25) bem Iieves the conaition to be due to damage of the tubercle bacillus 
to the diffuse mechanism of the body by non-specific trauma, causing the lesion to locate in the ear. The less virulent the acute infection, the more tuberculosis factors step to the front. The tuberculosis is the underlying latent condition which dominates the clinical picture. Guthrie (19) states that tuberculosis of the ear has been much rarer within the past ten years and that Turner (47) was reported to have said that suppuration of the middle ear in infants under one year of age is tubercular in fifty percent of the cases, and possibly due to contaminated milk. (49) (This conclusion was based on a survey in scotland). It is fortunately very rare on the North American continent. Manifestations of syphilis in the tympanic cavity are extremely rare. Mounier, Kuhn and Edward (26) have studied this problem quite thoroughly and report that middle ear infections in syphilis are independent of the syphilitic infection. The bone lesion however, is classified syphilitic.

The frequency of otitis media differs with the different data collected, however, a fair view is given by Tvermoes (36), from an observation of 768 middle ear inflamations between 1928-1932 inclusive. This showed 19.3 men, 21.3 women, and 59.4 children. Curves showing frequency from month to month demonstrates no striking regularity except from the low numbers, during the The most frequently recovered inicro-organisms from the inflamatory conditions of the ear is the streptococcus in one or other of its varieties, a haemolytic streptococcus being the causal organism in many cases, especially in those associated with influenza. Next in frequency are the pneumococcus and pyogenic 


$$
\text { -ETIOLOGY-(9) }
$$

staphlococcus in that order. Other less frequent organisms are the pneumo-bacillus, Bacillus pyocyaneus, Friealander's bacillus, Bacillus tuberculosis, influenza bacillus, diphtheria bacillus, typhoid bacillus, diplococcus, intracellularis meningitis, bacillus coli communis, Neisser's gonococcus, Vincent's spirillum and bacillus, and the smegma bacillus. (47) (48) (49) (67)

(48) Of the monobacterial infections, that of the streptococcus hemolyticus is most likely to run a severe course quickly progressing to severe mastoid and intracranial complications. However, several varieties of the pneumococci are very virulent. When the primary infection is due to the Bacillus influenza of Kataseto (grippe) it causes hemorrhagic abcesses and a mucoid pus of slight fluidity. Sometimes the bacilli are soon destroyed by a secondary infection in many instances of the streptococcus mucosus. (49) This organism the Streptococcus mucosus capsulatis of Schottmuller causes a type of otitis and mastoiditis which differs considerably from the ordinary suppuration form. It is now regarded by most bacteriologists as belonging to the pneumococci rather than to the streptococci. It has a tendancy to grow in chains and is not lanceolate in shape, but it has a thick capsule, and is soluble in bile and gives fermentation reaction like the pneumococci. It is now classed as a Type II pneumococcus.

(67) The character of the invading organism and its virulence are potent factors in determining the clinical picture; this together with the variation in resisting power of individuals explains the difference in the course and termination of the a.tacks. 
-PATHOLOGY-

(49) The pathological changes which occur in acute middle ear (infections) suppuration and acute middle ear catarrh are essentially similar and differ only in degree. They resemble the changes which take place in acute inflamation of nasal or any other mucous membrane, modified by the shapes and relationships of the middle-ear cleft. In all but the rarest instances infection reaches the tympanic cavity by way of the tube. The first change is an intense hyperemia and swelling of the mucous membrane. This is rapidly followed by the outpouring of an exudate, which is at first serious, but after a short time becomes seroor muco-purulent from diapedesis of leukocytes and shedding of epithelial cells. The eustachian tube takes part in the process, and on account of the narrowness of the lumen at its tympanic end, speedily becomes blocked. Leakage of the fluid from the tympanum into the throat becomes thus impossible. The mucous membrane in the meantime has become swolien to ten or twenty times its normal thickness, so that with the continually increasing exudate and the narrowed cavity, there is considerable tension, which causes severe pain. The tympanic membrane becomes buldged outward and sooner or later gives way and allows a copious discharge of pus. If, however, the arum membrane does not rupture early, the purulent exudate is forced back into the mastoid cells and may fill them completely. Perforation of the drum is not a mechanical process, but is preceded by small cell infiltration of its layers with destruction of part of the fibrous net-work. In a large prom portion of cases perforation occurs before the mastoid cells are 
-PATHOLOGY-(2)

involved to a serious extent and the discharge of pus is followed by a gradual recesaion of the inflamation, lessening of the discharge, and finally healing of the perforation and the return to normal.

Many times the perforation is too small or the pus is too thick for the free drainage and only partial relief of pain is obtained and the healing process is much delayed. A few days after perforation healing of the edges begins to some extent, and the hole tends to become smaller and smaller. If there is at the same time, a copious secretion of pus, there is a recurrence of pain and danger of the pus being forced into the mastoid cells. When there is a delay of some days before perforation occurs and the inflamation continues, the mastoid cells are nearly always involved. When the subsequent drainage is set up, the mastoid cells may clear up, but on account of their complex arrangement the drainage of the distant cells must be imperfect at the best. Healing is protracted in these cases and may last several weeks. Histological changes-mucous membrane becomes hyperemic and edematous. The normal cubical epithelium of the tympanic cavity becomes columnar and ciliated during the course of an acute inflamation. In the normal condition ciliated epithelium is found only in the tube and around its tympanic orifice. 
Because of the difference in the clinical picture arising out of purulent otitis media in the infant and adult, it becomes necessary to discuss the two separately.

It is important to note that otitis in infancy is not infrequently poor in symptoms, and takes an almost latent course. Nevertheless, it is necessary to learn the symptoms of the typical, fully developed otitis before attempting the diagnosis of latent forms. Acute otitis media is the most frequently overlooked af fection of infancy and childhood (Emerson).

(32) With the typical otitis of infancy, one must distinguish between subjective and objective symptoms. The subjective symptoms are first of all, pain, which appears especially at night, and therefore causes sleeplessness. Of course, exact observation of the infant is necessary to find out whether he is in pain, as it is arually only from about the 4 th month on that he calls attention to the ear by touching it constantly with the hand, rubbing: the outer ear ete. But with careful observation it is possible to recognize the pain in the ear earlier. Here, small details often prove decisive. One finds for example, that the child responds to every contact with the ear with crying, that it always wants to lie on one side, which is frequently the affected side, when no otitis externa is present, that for the same reason, it always nurses from one breast only, that it stops nursing now and then and cries out, when the movement of the Eustachean tube in connection with nursing causes pain; that the child cries out in pain in the midst of quiet play. Of course, pains in the ear are not absolutely conclusive evidence for otitis media, as they may 
also be caused by an otitis externa, but here the differential diagnosis may be made by simply looking at the region of the ear. Of the other subjective symptoms of acute Otitis, that is headaches, subjective noises in the ear, hardness of hearing and dizziness, one can make no use of, of course, in the diagnosis of otitis in infancy, but they are of great importance in otitis of older children.-W The objective symptoms are therefore of decidely more value. Here belongs first of all fever. In contrast to otitis media of adults, we meet the highest fevers here that are possible at all. Temperature of $104 \mathrm{~F}$. and $105.8 \mathrm{~F}$. are known. This fever is so characteristic that Gomperz rightly recomended that in all cases of feverish affections in infants, the ear should be examined, even if ear symptoms appear to be lacking. These high degrees of fever are found above all during the time when the suppuration has no free outlet. If paracentesis is performed, or if the pus perforates the ear drum spontaneously, fever should continue, but it should--especially in case of paracentesis-m show a lytic fall. If this is not the case, one should think of retention of pus, and now and then even of a beginning complication (meningitis, sinus thrombosis), especially when some other affection is present aside from the otitis (angina, bronchitis), which may also begin with high temperatures. Here it should be mentioned that a critical fall of temperature after paracentesis (collapse temperature) is prognostically more unfavorable, as, according to Alexander, it is not infrequently caused by a beginning meningitis.-It is of great interest also that the fever curve of infants otitis before paracentesis, fand there, also shows an intermittent character, 
without the presence of a sinus thrombosis.(2Z)In nursings the aural symptoms may be obscured by severe general symptoms. Bilateral otitis isn't always accompanied by a higher average temperature; as it is in adults; it may evolve with an insignificant $r i s e$ in temperature. The general course of the fever in infantile otitis is distinguished by absolute irregularity; 1ight cases may show a high fever and severe cases, slight fever. Rrequently deflections in the fever curve have no apparent cause; the individual power of reaction of the organism seems to be the determining factor. An initial high temperature 102.2 F., in favorable cases shows a lytic drop in a few days; it is usually of a remittent type. A high continuous fever from 104 F. to 105.8 F., or a fever of long duration points to another disease or complication; likewise a too rapidly lowered or a subnormal temperature is an unfavorable sign. Too large or too small daily variations indicate that the disease process hasn't terminated. Paracentesis in older children usually causes a drop in temperature; in children from one to two years, it scarcely affects the temperature. Antrotomy is necessary in children more frequently than in adults, especially in nurslings. There is usually a lytic drop in temperature after the operation. Complications (sinus thrombosis, meningitis) occur more frequently in children than in adults. In infantile otitis (and sinus thrombosis) there is more frequently an undulating temperature curve without a demonstrable cause. In view of the wide variation in temperature curve in acute otitis media in children, fever has less value for interpretation of the clinical picture, and as an indication for surgical intervention 
than in adults, and may be evaluated only in conjunction with the general and local symptons. $(32)$ hills seldom develope in infants. But this intermittent fever also must go down after the perforation of the ear drum, as in the opposite case it has a very different significance. In this connection, it should be remarked that the (infrequent) genuine sinus thrombosis in early childhood not infrequent1y takes its course under the guise of a high continua, whereby we can deduce that an intermittent fever curve with the otitis of infancy is to be evaluated very differently from the same curve with the otitis of aduIthood.--In just these cases, where otitis begins with high fever, one finds not infrequently (possibly partly due to the high fever) meningeal symptoms as well:--great prostration, sopor, nostril breathing, sudden unrest, convulsions, cramps in the face and extremeties, crying out in sleep, delirium etc. In these cases, however, the typical symptoms of suppurative meningitis hardly appear (stiffness of the neck, concave abdomen, Kernig, cloudy 1iquor). One has much more the impression that the above mentioned meningeal symptoms are not so much an expression of an independent suppuration of the meninges as the results of a septic affection. of course, attention must be drawn to the fact again that the meningeal symptoms enumerated need cause no anxiety when they appear, with the ear drum intact and disappear after perforation.-The dyspeptic symptons (vomiting, diarrhoea, constipation) have no connection with the meningeal symptoms and these are so very characteristic of the otitis of infants.

(63), (65), (66), There seems to be a clearer comprehension than formerly. The present consensus:-a relation exists between 
the two conditions, the one in the ear and the disturbed gastro intestinal function. Today no one of authoratative rank advocates operation on the ear unless a diagnosis of otitis has first been established. ( 32 It is still a question whether these symptoms are due to toxines entering the blood, or simply to the fact that the child swallows the pus draining of through the short, wide Eustachean tube. It is only certain that frequentiy otitis is the cause of the feverish 'Digestive system catarrht of infants. The inflamatory symptoms in the upper air passages (tracheitis, bronchitis) can be explained similarly to the dyspeptic symptoms. They not infrequently accompany otitis. If the ear is examined in these cases, one not infrequently finds swelling of the praeauricular glands, to which Gomperz, first of all, called attention. As, in these cases, the tissue surrounding the gland, is inflamed as well, and the entire parotis region may appear swollen. Of further interest is the secretion, which must be judged with caution, especially where there is an otitis externa, and an otitis media present at the time. We know, that the externa as well may produce rather profuse secretion, so that in a given case, it is not always easy to say, whether the secretion comes from the middle ear or from the outer auditory meatus. This question can sometimes be answered very quickly, if the secretion shows an admixture of mucous, which must come from the middle ear. But if that is not the case, repeated examination is of ten necessary to determine the source of the secretion. One must avoid drawing extensive conclusions from the foetidy of the secretions, also, in these cases. The secretion may be foetid with genuine otitis of infancy, as well as with otitis externa, or with combinations of the two affections, as the 
secretion of the ear tends in infancy, to become foetid very easily, possibly due to the narrowness of the outer auditory canal. One must always consider that the secretion with infants (and with adults as weIl) may take on a foetid character for two reasons:first, because of a hindrance to outflow; second, because the suppuration is accompanied by destruction of bone, which occurs in infants above all other infections, especially after scarlet fever. In the first case the foetidy of the secretion will disappear with proper treatment, rapidly; in the latter case, it persists. Therefore, one should speak of foetid secretion only when the case has. been under treatment for some time. Corresponding to changes before the ear, we also find redness of the skin behind the ear and this therefore feels warmer. But the retroauricular glands are usually not swollen, as long as the skin of the auditory canal does not take part in the inflamatory process.

The otoscopic findings are of special interest. The statement of earlier authors that otoscopy is impossible with infants and new born babies has been disproved by Gomperz. (45) It is well to approach the infant at feeding time when the attention is concentrated on the breast or bottle. Once crying or struggling takesplace, injection of the vessels of the drumhead and even a little buldging occurs. Pressure in front of the tragus, which is said to cause pain, should be avoided too. While the infant's tympanic membrane more or less equals in size that of the adult, the entrance to the meatus is small; having negotiated this, the drumhead, instead of being found to face the observer at a comparatively easy angle, as in the adilt, is here somewhat on edge, 
and not easy to see. (32) we use in these cases the small ear funnels described by Gomperz, and press the inserted funnel towaras the base of the auditory canal downwards, whereby the examination of the ear arum is made much easier. If the otitis has already perforated, we see the pus, which is expelled from the depths of the midale ear with pulsatory motions. An exact examination of the ear drum is very difficult, but in most cases of genuine otitis, it is not necessary, as at this age, hardy any other form of midale ear suppuration comes into question than acute otitis. The situation is entirely different if the otitis has not yet perforated. One should not expect that the otoscopic pictures which one is accustomed to see in adults, with acute otitis, should be repeated with infants. That is not always the case. We must consider that the ear drum after birth and in the first months of life is thicker, and surprisingly more resistant to rupture than in the adult, that especially the epidernis coat of the ear drum, has a relatively great thickness. That explains the fact that with a very much swollen epidermis, the ear drum itself, with severe inflamation, may only appear greyish red, whereby, however, the details of the ear arum (folds, short process of the malleolus) soon become invisible. One must therefore guard against negating the suppurative character of the otitis--as Alexander, repeatedly emphasized--itith such ear drum findings, especially when they are accompanied by fever. But the state of affairs may be complicated still further, in that with the described slight findings on the eardrum, the fever recedes just before the spontaneous perforation, because a circumscribed suppuration has formed in the middle ear, and the collateral in- 
flamation has gone down. In these cases also one can make mis-' takes, in prophesying for the future, if on the basis of the slight changes on the ear-drum and the receding fever, one diam gnosis a slight otitis, in the process of healing, and a short time later, one is surprised by the appearance of suppurative secretion. Therefore, the findings on the ear drum in infants are less reliable, in otitis, for the dignosis, and their value for prognosis, in infants, as in adults, is only slight.

In contrast with the infant, the clinical picture of purulent otitis media in older children and adults is much more definite and more easily comprehended.

The onset of an attack of acute purulent otitis media is usually sudden, following a "cold" an attack of grippe, or occurring as a result of one of the exanthemata. There is usually a prodromal stage lasting a few hours during which the ears feel "full", the patient's voice sounds unduly loud (autophony) and he thinks there is some obstruction of the external ear. The feeling of fullness becomes more marked until it becomes a severe pain, which is sharp lancinating, throbbing and boring in type. It is generally continuous, but with more acute exacerbations at times and like tooth-ache, it is usually worse at night. It is at first confined to the depths of the ear, but soon radiates out over the side of the head, forwards towards the temple, and backwards towards the occiput. It is intensified by actions such as yawning or sneezing which tend to increase the intratympanic pressure. (49) (47) (48) (67)

(47) In the more severe forms the pain may be almost unbear- 
able, but it is generally much relieved when perforation of the membrane occurs, as pain in the ear is caused by liquid or air under pressure. However, in influenzal cases associated with intense ear-ache, the pain may remain unabated for some days after rupture of the membrane. In the early stages of a severe infection, the ear may ache even before the filling up of the cavity with fluid. If the drum is opened at this stage, the imprisoned air hisses out and the pain is relieved. When the inflamation is mild, the discharge is at first thin and yellowish or pink, but after a day or two, it lessens in quantity and becomes thicker and more purulent. After flowing for a period varying from a few days to a few weeks, the discharge dries up, the perforation heals, the drum gradually regains its normal appearance, and the hearing returns (49). There is but little pain in cases where there was a perforation of the drum previous to the attack, or a thin cicatrix that easily mptures. The otitis of tuberculosis or syphilis is usually comparatively painless. (48)

In most cases, in addition to pain, there is some degree of tenderness on pressure over the mastoid--antrum or tip of the mastoid. It will be remembered that the antrum is part of the middle ear cleft, and that there is a communication of the tympanum with the mastoid tip cells at a point directly below the round window; hence this symptom does not necessarily mean that the bone of the mastoid process is envolved in the inflamation (47). Early mastoid tenderness during the first $f e w$ days of the illness is not of serious import, as it passes off as a rule as soon as the discharge is established. Alexander has called this early tenderness'mastoidism'. Recurrent or Ilate' tenderness indicates that the mastoid is seriously involv- 
ed, and forms one indication for the Schwartze operation (47). The longer the inflamation lasts without free discharge, the more apt is the mastoid to become involved. Late paracentesis may not be enough to avert an acute mastoiditis. It not uncommonly happens that after perforation the discharge ceases and the pain returns. This means that the perforation was too small and has closed over. Unless this is treated promptly, an acute mastoiditis is apt to result. (49)

In adults, fever (temperature of over $100 \mathrm{~F}$. ) is usually absent. In children and young adults it lasts some days, ranging from $100 \mathrm{~F}$. to $105 \mathrm{~F}$. before the advent of the otorrhea and of ten a few days thereafter. In these cases where the temperature persists after the advent of the otorrhea, the question as to whether or not the infection has spread beyond the tympanic cavity becomes one for serious consideration. If the general status of the patient remains good, if the sensorium remains clear, and if the pain remains slight, and no tenderness appears behind the ear, there is no cause for alarm, nor is operative interference indicated (67). In the discussion of fever in infants is found a comparison with that of adults. (22)

It requires a certain time for the body economy to establish its lines of resistance to the invasion, and until this is established, the temperature is likely to continue. (67)

Finally the fever may continue because the original lesion, the rhinitis, pharyngitis, bronchitis, pneumonia (especially in children) or typhoid may not yet have subsided. (67)

In the early stages there is only slight impairment of hear- 
ing, but after a few days deafness usually becomes much more marked. Tinnitus is also generally complained of and is in most cases of a throbbing character, due to the pulsation of the dilated vessels in the tympanum. Vertigo is not a coramon symptom in acute inflamation. Facial paralysis occurs in a small percentage of cases. (47) Otorrhea begins usually from one to three days after the advent of the disease. In chilaren the rupture of the drum may be delayed because there is an outflow of pus through the Eustachian tube. In rare cases the otorrhea begins a few hours after the commencement of the disease. On the one hand we may be dealing with an abnormally thin drum, or with a thickened drum from previous catarrhal attacks.

At the commencement the otorrhea is mostly serous in character, or serosanguineous; generally it is profuse. Later it becomes thicker and more purulent. It contains the exciting organisms in abundance.

As the disease progresses, if toward resolution, under appropriate treatment, it generally subsides and in from three days to five or six weeks it disappears. In (49) influenza the exudate is thin pinkish pus which only becomes yellow after several days. The appearance of the drum. This may differ or vary according to whether perforation has already occurred. (47) If it has not, the otoscopic changes of the membrane to be noted in a mild case are first injection of the handle of the malleus and the appearance of the fine vessels running from the umbo to the periphery, that is, a radial injection of vessels. The affection may stop at this stage, the tympanic membrane and cavity gradually returning 
to normal. If the inflamatory condition progresses the membrane loses its polish, the blood vessels of the arumhead, usually collapsed and lacking in colour, stand out vividly and the membrane buldges. With buldging, in whole or in part, there is absence of the light reflex. The buldging is at first only to be observed in the posterior half of the membrane; the hammer handle can still be distinguished and the anterior half of the membrane, which lies more in shadow, has a bluish tinge. If the inflamation does not subside at this stage, it passes into the more severe form in which perforation is almost invitable. The whole membrane becomes very red and convex and the hammer handle can no longer be recognized. At one point usually in the posterior half of the membrane, a yellow spot appears which, on careful examination, is often seen to pulsate; it is here that the membrane will give way. In some instances a nipple-shaped projection, surmounted by a yellow spot, appears on the membrane. (49) In severe cases associated with an attack of influenza the drum membrane shows hemorrhagic spots or bullae: These may apparently cause acute pain in themselves, since occassionally when they are pricked, the pain subsides even though the drum itself has not been punctured; in (47) the course of time these burst and discharge their contents into the meatus. In many cases the patient is not seen till the epithelium on the outer surface of the drumhead has desquamated, so that on otoscopic examination all that the observer sees is a white mass of cast-off, sodden epithelial flakes. Before the appearance of the drumhead can be observed, the ear must be syringed gently with a lukewarm solution of boric acid and the meatus dried out with cotton mops. 


\section{-SYMPTOUS AND SIGNS-(13)}

One observer (45) describes the changes in the drumhead as follows: The blood vessels of the drumhead, usually collapse and lacking in colour, stand out vividly--next, the inflamed tympanic mucosa shows through, casting a blush upon the face of the drumhead. The insertion of the membrane into the tympanic ring loses definition. The deep meatal wall, now growing angry, refuses to be distinguished easily from the arum skin itself, the pearly colour of which remains for a while in front of the umbo; even this disappears. The handle of the malleus is difficult to see; only its short process stands out as a landmark. The posterior superior quadrant may now begin to sag. It is of course, this area which one sees blown out by inflation in the quiescent drumhead. Most probably the presence of abundant small vessels in the anterior part gives to it the very deep colour during inflamation, but just because it appears to buldge, the best therapeutic result will not follow its incision in acute otitis media; and by entering the knife to high and rather near the short process of the hammer bone, it is possible to severe and cause damage to the main blood supply of the drumhead. It is surely better for several reasons to incise the lower part.

When perforation has occurred, the meatus is $f u l l$ of pus, and it is generally necessary to syring the ear, in order to obtain a view of the drumhead. The perforation may be so small as to escape detection by the eye; but if the inspection of the membrane is continued for a short time a pulsating spot of light is often seen and this is especially noticeable in the reflection of light from pus exuding through the perforation. The perforation is generally 
very minute, and is most commonly seen situated about the center of the arum posterior to the malleus. If in doubt as to whether a perforation or not, Siegle's pneumatic speculum should be used. By applying suction a drop of pus will appear and reveal the perforation.

The discharge, at first abundant, gradually diminishes, and in favorable cases ceases after a period varying from a few days to two or three weeks. It may, if untreated, continue indefinitely; the condition then passes into the category of chronic middle ear suppuration.

(48) In cases where the inflamation is in the attic, the membrana tensa may appear nearly normal as to color and position, and yet rupture sometime later with an abundant discharge of pus from the attic. When, however, the attic and mastoid antrum, contain pus which can not readily drain into the atrium because of swelling of the mucous membrane about the ossicles, this pus will sometimes burrow underneath the skin of the auditory canal and find an exit either at some point within the canal or behind the auricle. Those cases in which no perforation occurs run a tedious course and some permanent imparement of the hearing usually ensues. The duration of the disease from the occurrence of a perforation to its closure is very variable. In cases where the perforation occurs early, it may remain open only for a few days. Three or four weeks are ordinarily required for the closure of a small perforation.

If the perforation is large it will probably remain open long after the suppuration has ceased, to finally close by cicatrical material destitute of all fibers of the membrana propria, and will 


\section{-SYLPTOIS AND SIGNS-(15)}

buldge inward and outward, with the varying intratympanic pressure.

(67) With resolution the membrana tympani becomes paler and thinner; meanwhile the outline of the malleus becomes visible. The hearing gradually returns toward the normal.

(48) Extensive destruction of the structures of the middle ear sometimes occurs during acute otitis media. This is especially apt to take place when the disease appears as a complication of scarlatina, variola, or diphtheria. The whole of the drum membrane and all of the ossicles may come away within a few days from the onset of the middle ear disease as an enormous slough. In other cases, ulceration, starting from the perforation proceeds more slowIy, but it accomplishes equally disasterous results.

Retraction of the drumbead and a pink discoloration with a temperature of 102 or $103 \mathrm{~F}$. is a frequent symptom of closure of the pharyngeal tube mouth in acute rhinitis. An extension to the tymm panum is not certainly indicated by redness and congestion of the periphery of the drumbead and the malleus handle. Such symptoms subside as the result of nasal treatment and gentle inflation. The making of an open wound through the drumbead into the tympanum is to be avoided if possible and is only certainly indicated when pain and buldging are present.

Jerkovic (46) after investigating both the quantitative and qualitative components of the blood in eighty-five cases of ear conditions draws the following conclusions:

I. It is impossible to differentiate an uncomplicated acute otitis media from an acute otitis media with mastoiditis 


\section{-SYMPTOMS AND SIGNS-(I6)}

on the basis of the blood picture.

2. In otitis due to the streptococcus mucosus the blood picture will reveal the presence of a perisinous and extradural abscess with a considerable degree of certainty.

3. It will be of aid also in the diagnosis of acute exacerbations of chronic processes.

4. Most of ten it makes possible the diagnosis of severe complications.

5. In cases of severe complications, it will aid in the establishment of the prognosis.

6. It is a reliable index of the postoperative course of the disease.

Curcio (28) examined 60 cases with acute otitis media and studied the differences in the size of the pupil. Anisocoria was found twelve times, mydriasis seven times and myosis five times. He advances the explanation that myosis follows pressure of exudate or the fibers of the sympathetic nerve in the middle ear, producing paralysis of these nerve fibers. The condition usually accompanied a perforated drumhead, but nevertheless there was inadequate drainage of the ear. Typical mastoiditis was absent. The combination of mydriasis and sharp pupillary reactions, he comprehends as an expression of irritation of the dilating fibers. This was found in patients who presented irritative signs from the labyrinth-momiting, dizziness, and aystagmus. A few days postoperative the pupils were again normally equal.

He concludes that in the floor of the tympanic cavity, there are fibers from the sympathetic nerve, and he believes that signs 
obtained from the pupils are significant indications for operative intervention. These signs take on special significance in traumatic cases. They bespeak on injury involving the mucous membrane of the tympanic cavity ano should be considered as an indication for operation.

Riegele (12) in studying the nerves of the inflamed tympanic membrane in preparations stained by the Bielschowsky method, observed that in the part of the nervous pericapillary plexus infiltrated with leukocytes during inflamation of the tympanic membrane in man, degenerative changes occurred in the capillary nerves. This process appears to go so far that the fibrous ti ssue elements which surround the capillary nerves can enter into the structure of the degenerating sheaths.

Fioretti (30) has produced by irritation in the region of the Eustachian tube, pain in and about the eye, which is one of the most characteristic signs of petrossal suppuration. He believes that when this pain occurs without other accompanying symptoms, it is due to irritation of the sympathetic nerve, in the pericarotid plexus, the irritation eventually reaching the ciliary ganglion.

Leidler (23) calls attention to tachycardia in most cases which exhibit septic temperature curves. The presence of this at cominencement of otitis is to be regarded as a grave sign.

Pragier (13) states that one type of acute inflamation of the petrous apex coincides with the early stage of acute otitis media and is shown by hyperemia of the bone, swelling of the mucosa, and the presence of an exudate in the air containing cells. The author calls this condition-m"petrosismus" to differentiate it from "pet- 
rositis", it is analagous to mastoidismus. The pathway for this condition has been brought out previously.

It is interesting to note that Asherson (17) believes that in the majority of cases of acute otitis media the tympanic cavity alone is involved.

McKenzie describes thirteen cases of a persistent suppuration Irom the ear, which were found to be spontaneous rupture and evacuation of a brain abscess. At the onset the discharge is usually sudden and coincides with relief of pain and headache. It is generally copious and persistent, the quantity being apparently greater then can be produced by mastoid and middle ear spaces alone. The pus is thick and not infrequently fetid.

Deserving of special discussion is the otitis occurring in the exanthemata and specific types.

(47) The incidence of otitis media in influenza varies great1y. Earache comes on suddenly from the first to the third day of illness. Otoscopy shows dark-red vesicles filled with blood on the drumhead or posterior meatal wall, though mastoid tenderness is not yet present. Paracentesis is followed by considerable bleeding, and later by a profuse serosanguineous discharge for several days. Later still the discharge becomes purulent. The infecting organism is usually the streptococcus hoemolyticus. Bayer points out that acute inflamation apparently limited to the attic, may occur in influenza. There is at first congestion of the membrana flaccida followed by buldging and the formation of a blood blister which extends to the meatal wall. Lastly, a perforation occurs, but before this paracentesis should be performed. If a cure is not affected in this way, attico-antrotomy is indicated. Erailyi (7) in reviewing 


\section{-SMUPTOMS AND SIGNS-(19)}

the Influenza epidemic of December 1932 and January 1933, beginning then, states that infection of the middle ear was a common complication. Although these of ten healed spontaneously, he felt that paracentesis was always advisable since it has no disadvantages. Mastoid complications were not seen in infants, but occasionally signs were seen in children. Conservative handing sufficed here.

(47) In scarlet fever the causal organism is the streptococcus. The otitis may be due to an extension of infection from the nose and naso-pharynx, along the Eustachian tube, or may be a local manifestation of the general blood infection. Eareche, when present is a fairly reliable sign of ear mischief. Ear discharge occurs, however, twice as often without pain as with it. In the majority of cases, the discharge is purulent, less frequently it is mucoid. The discharge has a foul odor in cases complicated by diphtheria.

Gardiner finds that from 6 to 10 percent suffer from purulent otitis media which occurs most frequently in the first or second week of illness. Rade (5) after a survey of 2,835 cases found that it occurred in 12.64 percent and was bilateral in 31.5 percent. Otitis developed in 28.64 percent between two and three years of age, but in only 3.12 percent between twelve and fourteen years of age. In most cases otitis occurred early in scarlet fever. In 23.6 percent during the first three days, and in 17.2 percent during the fourth weck as a secondary manifestation of scarlet fever. Only a small number of otitis media developed between these two periods, and these usually resulted not from scarlet fever itself, but from complications. Mastoiditis occurred in patients 
who no longer had any complications except otitis and in whom otitis developed at the beginning of the disease. Of 41 patients who died of scarlet fever, eight had otitis, but only one died from the sequela of the otitis.

Abrams and Friedman (4) in a survey of 4,315 cases of scarlet fever drew the same conclusions as Rade. The peak was reached in children one year of age; one out of every two had purulent otitis meàia.

The incidence of scarlet fever is greatest in March and October, whereas most otitis occurs in February, April, and June. Ninetymone percent occurred in the first decade, and fell to 1.9 in third decade.

First week time of onset of otitis 35 percent

\begin{tabular}{|c|c|c|c|c|c|c|c|}
\hline Secona & $\|$ & $\|$ & $\|$ & $\|$ & 11 & "I & 25.4 \\
\hline Third & $\#$ & II & ॥ & $" 1$ & $\|$ & $"$ & 15.1 \\
\hline Fourth & " & " & " & $\|$ & " & " & 9.9 \\
\hline
\end{tabular}

Among 574 cases, 210 were on the right side, 153 on the left side, and 211 bilateral. Onset in soine cases was painless and without symptoms; discharge of pus being the first indication.

Importance of early myringotomy is agreed on by practically all authors. In the cases where the drum was incised, the average duration of drainage is 22.2 days. Ears where the drum ruptured, 28 days is the average. In these cases the drum was incised in 26.7 percent anö opened spontaneously in 63.3 percent. Mastoidectomies following incision of drum 25.3 percent, and 74.4 percent followed spontaneous rupture of the drum, so 14.3 percent ears with drum incised required mastoidectorny, as compared to 24.1 
percent of ears in which the drum ruptured spontaneously. (47) In measles according to Gardiner, the onset of otitis media usually occurs in the first or second week, but it may be late in the sixth week. Only in the early cases is there pain. The perforation is anterior as a rule, and the otitis is not so severe as that met with in scarlatina, The organism present is a streptococcus or pneumococcus. Acute mastoiditis is as a rule as free from pain as the otitis media. The only aign that can be depended on is sagging of the posterior-superior wall of the canal. In some cases extensive destruction of the membrane takes place.

(47) Otitis media occurs in seven percent of cases of typhoid fever, usually during the stage of recession. Pain is rarem Iy a marked symptom. The organisms present are those usually associated with acute middle ear suppuration.

Acute purvient otitis media in diphtheria as observed by Bergh in 2,425 cases. There was envolvement of the ear in 121 percent, and was one sided in 62.2 percent. There is considerable variation in the frequency of otitis from year to year and in different seasons. The third quarter of the year shows the lowest incidence. Largest number of cases occur from one to six years; although the largest number of patients with diphtheria is six to eight years. The frequent occurrence of otitis here is one to nine years with exception of the eighth year. Nasal diphtheria is the most dangerous for otitis. About one-half of the otitis occurred after the twenty-first day. Otitis has no effect on the mortality from diphtheria. About two-fifth of otitis are afebrile. Prognosis is good as to life and mastoid complications. 
Guthrie (19) states that tuberculosis of the ear has become much rarer in the past ten years. This forn of suppuration of the middle ear is usually gradual and painless in development and the surrounding lymph glands are much enlarged. In about 50 percent of cases there is facial paralysis. Assheuer (16) is of the opinion that definite conclusions as to the specificity of the otitis can not be made from the clinical picture and confirmation of the diagnosis of tuberculosis otitis must be sought in bacteriologic examination of the discharge; in biopsy; in inocculation of animals with secretion or granulations; or in the focus reaction (Herdreaktion). This reaction consists in the appearance of hyperemia of the tympanic membrane and a possible exacerbation of the otitic symptoms simultaneously with the cutaneous and general reaction to the subcutaneous injection of tuberculin.

Despons (25) Primary tuberculosis is quite rare. It is observed clinically as acute otitis media. with fever, which then develops into acute mastoiditis. The evolution of the lesion is slower and the acute stage is longer than in other forms of otitis. This he believes suggests the tuberculosis nature of it.

(19) A complete mastoidectomy must be done if the disease is to be erradicated. The general condition of the patient at the time determines the prognosis, which isn't always hopeless. Otitis media due to the Fneumococcus mucosus (streptococcus mucosus) or to Friedlander's Bacillus presents important characteristics. There is an acute onset clinically characterized by painlessness and absence of fever, but in more than one-half of the cases the tympanic membrane does not rupture or the trifling 
discharge cease very early. This is followed by a long interval, during which the drumhead presentsan almost normal appearance, and the patient has only slight deafness and tinnitus, and then an intracranjal complication, especially purulent meningitis, suddenly appears. About three months on the average, may elapse between the first onset of the disease and the appearance of the complication.

Rollin (14) believes the demonstration of the cause of mucous otitis is essential to the diagnosis, because of similarity in cultural characteristics of streptococcus and relative strains of pneumococi, he feels that a direct smear should be made as well as a culture. When stained with thiomine the smear shows a wide Iight red halo around streptococcus mucosus while streptococcus lanceolatus, which/otherwise similar shows no capsule. In contrast to otitis due to a hemolytic streptococcus, which usually begins with a rapid inflatory onset and a reddened tympanic membrane, mucous otitis is often insidious in onset and presents a pale tympanic membrane and a profuse mucopurulent discharge. The author describes eight fatal cases with necropsy in six. These six had. in common, a surprising course in that apparantly harmiess mucous otitis developed into rapidly fatal meningitis. Anatomically, they all had the same focus in the upper part of the pyramidal tract, namely a cell complex which is made air containing from the epitympanum. There was no direct connection, however, between these air containing cells and the antrum. Rollin believes that from this focus a subdural abscess sometimes develops, after which the special anatomic characteristics of the original focus disappear, 
so that a clear understanding of origin of theabscess is no longer possible. He stresses the need of both smear and cultures before one can establish positive diagnosis. He calls attention that in the course of mucous otitis the fifth week presents the most critical period. The tendancy of the lesion to reach and infect the perilabyrinthine cell tracts and the peripheral cell tracts is characteristic. Rollin reports six cases. He found three types of intracranial invasion: (1)Rupture into the labyrinth (2) rupture through to the porous acusticus internus and (3) direct spread to the dura. His final observation is significant. He found that too early operation makes danger of meningitis greater than with later intervention.

Eigler states that aside from 33 cases of otitis caused by Friedlanders bacillus reported by German, only 17 cases due to this organism have been reported in the literature. He notes two personal observations of this rare form of otitis,-..All the sporadic cases are severe and with few exceptions show a tendancy to develop severe local and general complications. In onset and evolution the condition resembles otitis mucosa. Most frequent in persons of micale age. General metabolic disturbances as diabetes, cirrhosis of the liver, which occur with relative frequency in this rare form of otitis, constitutes chief danger for patient, besides general weakness. In case of early recognition of the tiologic agent by bacteriologic examination (this should include nasal examination because of the frequent rhinogenous origin of the infection) early operation is advisable as in more than half of sporadic cases the patient died with suppuration of the bone, despite surgical interference. 
From careful evaluation of the symptoms and signs and consideration of etiology, a diagnosis of acute suppurative otitis media is possible as a rule; however, certain other conditions may give rise to confusion. Otalgia with otorrhea may arise from either otitis media or otitis externa. If the external auditory canal is not swollen and not painful to pressure, then the supposition exists that the patient has purulent middle ear disease. If the external ear is filled with pus which pulsates, the diagnosis of acute middle ear purulency can be made, even if no otoscopic examination is possible. An otoscopic examination isn't always possible in the very young. Severe pain, associated with intense redness and buldging of the membrana tympani are the characteristic early symptoms. A boil or furuncle will cause not only pain, but also discharge, and sometimes deafness. This is distinguished by extreme tenderness of the meatus which is absent in acute otitis media. The swelling is of ten so great as to completely close the meatus, causing deafness, and if there is discharge in addition, it becomes important to know whether there is also an otitis media. If a small speculum is introduced carefully beyond the swelling and the deep meatus cleaned, the hearing may be tested, and if normal, otitis media can be ruled out. Referred tooth pain associated frequently with the lower molar on/affected side is quite common. A normal drumhead with good hearing and a defective tooth will clear up the diagnosis here. An inflamed tonsil will give rise to pain in the ear, but isn't apt to give trouble in diagnosis. Among the rarer causes of otalgia is herpes oticus. In this condition pain is severe and may be accompanied 
by some deafness. Unt il the characteristic herpetic erruption appears, diagnosis is difficult, if not impossible.

Keen(33) in discssing the quickest and simplest method of determining the causative organism in acute infections of the ear and upper air passages states that in early states of acute otitis and acute throat infections, the causative organism is of ten found in pure oulture in nasal swabs, while swabs from tonsils and sputum give very little information, and the same applies to the middle ear secretions, obtained in the early stages. The reason is that in health, the nasal mucosa is practically always sterile. Pharyngeal swabs, on the other hand, al ways show numerous strains of organisms, many of them pathogenic. Therefore the presence of pathogenic organisms in nasal swabs has a definite significance. In 63 cases with acute otitis, the organisms cultured from nasal swabs were compared with those from tonsil swabs. The main findings were:-

Nasal swabs taken in first few days of acute otitis nearly always contain a pure culture of the organisms, which, later on, were recognized as the cause of the acute middle ear infection ( 47 cases out of 63). Compared with this a pure culture was obtained in tonsil swabing in only 12 cases.

The great value of nasal swabing applies chiefly in the cases of mucosus otitis in the pneumococcus groups and with the influenza bacillus. The difference is less marked in the case of hemolytic streptococcus, on account of their tendancy to cause tonsilitis. The organisms disappear from the days. In case of several pathogens fromberal swab, one must be very careful in deciding which organism is the cause of the otitis. 
Wirth (68) states in this same connection that in the first few days of an otitis media the causative organism is present in pure culture in the nasal passages in 75 percent of cases, wherees a culture from the throat always gives a mixed growth. In pneumococcus type III otitis, this method is of particular value. The author also finds that the organism in acute inflanation are 10calized on the surface of the nasal mucous membrane and he suggests that the spread of the infection in the mucosa is simular to the spread of erysipelas in the skin.

Reiniger (54) believes that puncture of the middle ear and bacteriologic examination of the fluid aspirated are a valuable aid in the diagnosis of atypical otitis media. The author recommends puncture with a long needle and aspiration of the fluid with a I cc syring. This enables one to determine immediately the existance of secretion and note its appearance. The fluid aspirated is transferred to both Gram stains and Voges agar plates are made from the broth suspension. The author cites many cases in which this method helped to establish the diagnosis. This may help deter mine whether a slow healing is due to a disturbance in pneumatization, to general disease, or to mucous otitis, presumably requiring an operation. In cases which from the istic symptoms, and in which subjective symptoms appear harmless, severe symptoms such as heacache, high temperature, vertigo may suddenly supervene. Puncture of thear may help determine if symptoms are due to otogenus complications or intercurrent disease bearing no relation to the ear.

Although with consideration of all the symptoms, a 
-DIAGNOSIS- (4)

diagnosis of purulent otitis media is possible as a rule, the state of things is much more difficult, with latent otitis in infancy, but one must admit that this diagnosis has been much disused. In many cases, it is not at all a question of latent otitis, but of an overlooked otitis. This mistake is entirely understandable. The symptoms are not always marked, or they are interpeted wrongly, so that there is no reason for examining the eardrum, which in these cases would show changes of slight or more pronounced degree. When one reconsiders such cases of overlooked otitis, however, one finds that there was an indisposition of the infant, ayspeptic symptoms etc., which were not recognized in their true significance. That an otitis can develope behind a perfectly normal eardrum may be true of isolated cases of tuberculous midale ear suppuration. Nevertheless, it is justifiable, considering the relative frequency of otitis very poor in symptoms in infancy, to divide these off into a separate group of diseases, and to describe them clinically uncer the name of "latent otitis". The reasons for this latency are various. If we exclude the cases in which otitis breaks out in the course of other severe illness (pneumonia), and frequently shows a slight non-suppurative character, and if we further exclude agonally appearing otitis, the following causes come into consideration for the latency. First, there are cases in which the pus comes from the nasopharynx and is sucked through the tube into the middle ear, without the mucous membrane of the middle ear taking much pact in the inflamatory process. This is seen infrequently in convalesence after severe illnesses, when the child swallows poorly and seldom, whereby the midale ear is poorly ventilated. 
$\rightarrow$ DI AGNOSI S $\rightarrow(5)$

The result is that the air in the midale ear is absorbed and the negative pressure in the midale ear thus produced, sucks the pus out of the nasopharynx. Further, there are cases, usually older children, however, in which the otitis has become habitual, and in which one is surprised by the sudden appearance of otitis. In all of these cases the otitis has a very mild course, as a rule, and disappears just as suddenly as it came. Another form of latent otitis is the midale ear inflamation caused by capsule bacteria (streptococcus, pneumococcus), which now and then appears in children. E. Urbantschitsch has described several such cases. It is well known, from the conditions among adults, that as a result of this infection, very extensive inflemation, may arise, with only slight symptoms.-The most frequent form of latent otitis in infants, however, is in connection with tuberculosis. Here belong those frightful cases, in which, in the course of a haemotogenic dissemination, the ear is attacked, also. In these cases extenm sive cestruction of the middle ear and inner ear may take place, accompanied by only very slight symptoms; these nevertheless, play only a small part in the serious generel affection practically. Then, there are cases, and these are rather frequent, in wich tuberm culosis of the middle ear shows a much more benignant course, and only betrays its specificity therein that it--if one may say it-m begins as a chronic otitis and remains a chronic otitis, in spite of the proper treatment. We should like to go even further, and say that also the cases of otitis in infants which begin in typical fashion as acute otitis, but then become chronic, in spite of proper treatment, were tuberculous otitis from the very beginning, 
or were genuine otitis in tuberculous infants. We know that tuberculous otitis can imitate every other form of otitis, therefore, also, the typical acute otitis. This possibility of error plays an importent part, in all probability, in just those cases, fortinately not very frequent in which an apparently ordinary acute otitis of infancy is followed by tuberculous meningitis or brain tuberculosis. In these cases, as well, there was probably not an ordinary acute otitis, but an acute tuberculosis of the middle ear. In all these cases, it is of course only now and then possible to diagnose the otitis before the secretion of the pus begins. But, especially here, not much is lost thereby, as early paracentesis could not materially change these latent beginning cases of otitis.-. So far, we have understood by latent otitis, only cases which begin poor in symptoms or without symptoms, but then give up their latency when the suppurative secretion begins. However, there are also cases of otitis in infancy, which not only began latently, but run their course as latent. Of course, such cases in this time of life are of no further practical importance, but they are important for the appearance of chronic adhesive processes in the midale ear, which cause very unpleasant ear symptoms in later life (subjective ear sounds, hardness of hearing, dizziness). 
-COMPIICATIONS-

A cetailed discussion of complications would be beyond the scope of this paper, however, mention will be rade of the various routes by which complications occur; and complications will be mentioned.

The apread of infection from the midale ear may occur in the following manner:

1. By way of the regional venous circulation to intracrantal structures; which takes place in most cases by means of a septic thrombus. This process is one of progressive damage to the endothelium of the venous channels. This may occur against the circulation of a retrograde nature.

2. Infection may be propogated by continuity of lesions of bone, that is by cellulitis or osteitis.

3. Utilization of a pre-existing passage, as: (a) preformed nerve and vessel channels, (b) embryonic interstices, and (c) the tensor tympani canal. Of particular interest in this connection is direct continuity of perineural spaces of the auditory, vestibular and (ofactory nerves with the pia-arachnoid membrane).

4. Lymphatics, however, the lymphetic circulation is of questionable significance as a pathway of infection from the peripheral parts to the intradural structures, because lymphatics connecting these structures haven' been satisfactorily demonm strated.

5. Through massive bone destruction and dehiscences, infection may leave the ear and find escape under the base of the cranium.

6. BIood stream. 
The complications are as follows:

Intracranial complicatione:

1. Meningitis.

2. Errosion of the carotid artery and fatal hemorrhage.

3. Extra-dural abscesses.

4. Gradenegos syndrome.

5. Brain abscess.

6. Sinus phlebitie and thrombosis.

7. Labrynthitis.

8. Thrombosis of jugular bulb.

9. Retropharyngeal abscess.

10. Mastoiditis.

11. Destruction of ossicles.

12. Chronic otitis media.

13. Chronic mastoiditis.

14. Osteomyolitis of the terporal bone.

15. Fetrositis.

General complications:

I. Septicemia.

2. Pyemia.

3. Metastatic abscesses.

4. Toxemia.

Tamarif (35) from a review of postmortem reports fron the general hospital in Vienna for the Jears 1905 1989 inclusive reports:

1. The mortality rate increases between the end of the first 


\section{-COMPLICATIONS-}

year and the age of forty.

2. At all ages and for all complications, the male has less resistance than the female.

3. Sinus thrombosis and septicemia constitute the greater proportion of fatal otitic complications, 415 cases in 1,013 .

4. In 143 cases metastasis were found chiefly in the lungs, but also in the joints, liver, pancreas and kidneys, but only in one case in the musculature.

5. In 376 cases meningitis was given as the calse of death, of which 76 cases were traceable to the labrynth route.

6. Cerebral abscess was found in 282 cases and cerebellar abscesses in 83 cases.

?. About one-third only of both the complications followed acute otitis.

8. The great majority of chronic cases leading to cerebral and cerebellar abscesses were associated with cholesteatoma.

This article should represent a very reliable statement of the present position of this aspect of otology. Although the apparent rise in death rate during the twenty-five years in question yields the very aisquieting information that the mortality rate has rather more than doubled in comparison with previous similar collections, further analysis shows that the previous figures were quite unreliable, since/corresponaing to Gruberts figures, it wes the exception to the rule to admit children to the General Hospital, and that in past time it was quite common to regard meningitis of unknown origin as the cause of death without any effort to trace its original source. 
1. With inflamation of the tympanum there is in the great majority of cases involvement of the mucous membrane of the mastoid.

2. Infection of the middle ear takes place in the great majority of cases by way of the Eustachian tube.

3. Otitis media occurs much more frequently in infants and children.

4. Otitis media in the infant presents a different clinical picture than in the adult.

5. In all cases of feverish affections in infants, the ear should be examined, even if ear symptoms appear to be lacking.

6. In infants a relation often exists between the ear and a disturbed gastro-intestinal function.

7. Otitis media is a very frequent sequela of the exanthemata.

8. It is thought to be justifiable, considering the relative frequency of otitis very poor in symptoms in infancy, to divide these off into a separate group of diseases, and to describe them clinically under the name of 'latent otitis'.

9. Otitis media frequently gives rise to severe intracranial and general complications. 
-BIBL IOGRAPHY-

1. Kopetzky, Samuel J.: Otitis Media and Petrosal Pyramid. Arch. Otomrhinomlaryn. Vol. 20, No. 3, p. 396:421 September 1934.

2. Glass, E. J. Gilroy: Blood Infection from Otitis Media. Journal of Laryngology and Otology, 48: 754. Vol. 19, No. 4, p. 516 November 1933.

3. Wolff, Dorothy:

A Brief History of Early Development of Anatomy of tiar. Laryngoscope, Vo1. XLIV, No. 1, p. 1. (January 1934)

4. Abrams, Jacob I.; Friedman, Samuel: Review Otitis Media of Scarlet Fever. New England Medical Journal, 209:494 September 7, 1933.

5. Rade, F.:

Otitis Media in Scarlet Fever. Ztschr, F. Laryngology, Rhino, Otology. (Teil 1: Folio oto-laryng.) 24:126 (May 1933) 


\section{-BIBLIOGRAPHY-(2)}

Abst. Arch. Oto-rhino-laryn. Vol. 19, No. 1, p. 102, January 1934.

6. Eigler, G.:

Otitis Caused By Bacillus Friedlander. Arch. F. Ohren-Nasen-u.

Kehlkopfh. 136:318 (October 14, 1933) Abst. Arch. Oto-rhinomlaryngology. Vol. 19, No. 5. p. 640-541 May 1934.

7. Erailyi, E.:

Otorhinolaryngologic Experiences in this years Epidemic of Influenza. Monatschr. F. Ohren. 67:1412 (Dec. 1933) Abst. Arch. Otorhinolaryn. Vol. 19, No. 5, p. 642. May, 1934.

8. Graham, T. 0.: Treatment of Acute Otitis Media In Acute Febrile Conditions. British Medical Journal. August 1933. Abst. Arch. Oto-rhino-laryn. Vol. 20, No. 1, p. 107. July 1934. 
-BIBLIOGRAPHY-(3)

9. Broch, w.:

10. Koch, F.

11. Vahldieck, W.:
Microscopic Demonstration of the Occurrence of Spontaneous Perforation in the Region of Shrapnells Membrane in Acute Otitis Media, Ztschr. F. Hals-Nasen-u. Ohren. 35:439 (April 1934)

Abst, Arch. Oto-rhino-1aryn. Vol. 21, No. 1, p. 100 Jankary 1935.

Severe Labryinth Complications in Acute and Chronic Otitis Media, Monatschr. F. Ohren. 67:1251 (Octo ber 1933) Abst. Arch. Otomrhinomaryn. Vol. 19, No. 5, p. 642 May 1934.

Is Distinction in Acute Mesotympanal, Epitympanal and Retrotympanal Otitis Media Ligitimate, Arch. F. Ohren, Nasen-u. Kehlkopfh 137* 187 (December 1933) Abst. Arch. Oto-rhino-laryn., Vol. 20, No. 4, p. 583 , October 1934. 
12. Riegele, I.:

13. Pragier, E.:

14. Rollin, H.:

15. Asherson, N.:
Changes in the Nerve Apparatus of Inflaned Tympanic Membranes. Ztschr. F. Hal s-Nasen-U-Ohren 35:139. (Feb. 1934) Abst. Arch. Otomrhino-laryn., Vol. 20, No. 4, p. 585, Octo ber 1934.

Clinical Reports of Inflamation of Petrous Apex. Monatschr. F. Ohren. 67: 1491 (Decernber 1933) Abst. Arch. Oto-rhino-laryn., Vol. 20, No. 2, p. 265, August 1934.

Mucous Otitis, Arch. F. Ohren-Nasen-u. Kehlkopfh 137:333 (December 1933). Abstracted from Arch. Oto-rhino-laryn., Vo1. 20, No. 3, P. 427, September 1934.

An Early Clinical Sign of Acute Mastoiditis. The Lancet, No. III of Vol. I, January 1935, p. 150 . 
16. Assheuer, H.:

17. Asherson, N.:

18. Uffenorde, $\mathrm{W}_{0}$ :

19. Guthrie, Douglas:
Tuberculosis of the Middle Ear. Ztschr. F. Hals-Nasen-u, Ohren. 33:322 (JuIy 8, 1933)

Abst. Arch. Oto-rhino-laryn., Vol. 18, No. 3, p. 393, March 1934.

An Early Clinical Sign of Acute Mastoiditis. The Lancet. No. 5 of VoI. I, p.294, February 1935.

Diabetes and Purulent Middle Ear Infection.

Ztschr. F. Hals-Nasen-u. Ohren. 35:385 (April 6, 1934)

Abst. Arch. Oto-rhino-laryn., Vol. 21, No. 2, p. 224, February 1935.

Tuberculosis of the Ear, Tr. Edinburgh (September 1933). Med.-Chir. Soc., 1933, p. 169; in Edinburgh Medical Journal. Abst. Arch. Oto-rhino-laryn., Vol. 21, No. 1, p. 98 , January 1935. 
20. Almour, Ralph:

21. Meltzer, Philip E.:

The Mastoid Cells: Their Arrangement in Relation to the Sigrnoid Portion of Transverse Sinus. Arch. Oto-rhino-1aryn. 19:326, March 1934.
22. Meyer, Liselotte: Ueber den Temperaturverlauf der akuten Mittelohreiterung des Kindes, Arch. F. Ohren-Nasen-u. Kehlkopfh. 135:77, 1933. Cited by Samuel Kopetzky \#l.

33. Leidler, Rudolph: Die Otogene Sepsis im Kindesalter, Wien. KI in-Wchnschr. 46:1128 (Sept. 15) 1933. Cited by Samuel Kopetzky \#1. 
Sauglings und Kindesalter, Wien, KIinWchnschr. 46:1426. November 24, 1933. Cited by Samuel Kopetzky \#1.

25. Despons, J.:

Sur un cas de tuberculose primitive de I'oreille chez I' $^{\prime}$ enfant, Rev. de laryng. $54: 387,1933$.

Cited by Samuel Kopetrky \#I.

26. Mounier, Kuhn, Edward.: Syphilis of the Mastoid and the Mastoid Region, Rev. de laryng. p. 734, 1933.

Cited by Samuel Kopetzky \#I.

27. Keleman, G.: Zur Pathologie des otogenen parapharyngealen Hals Abscesses, Zentralbl. F. Halsm Nasen-u. Ohren. 33:600, 1933 Cited by Samuel Kopetzky \#1.

28. Curcio, Gaetano: Reazione pupillare nelle otiti media purulente, Otomrhinolaryng. ital. 3:533, 1933. Cited by Samuel Kopetzky \#1. 
29. Rollin, H.:

30. Fioretti, Ferruccio: cronica colesteatomatosa riacutizzata, Rev. oto-neuro-oftal. 10:583, 1933 Cited by Samuel Kopetzky \#1.

31. Howell, Nancy $G_{\bullet}$ : The Value of Paracentesis In The Acute Specific Fevers, Proc. Roy. Soc. Med. 26:572, 1933. Cited by Samuel Kopetzky \#1.

32. Brunner, Hans: When Should the Practitioner Think of Otitis Media, In an Infant, Arsmedici, The Journal of the Am. Med. Assoc. of Vienna, Vol. XII, No. 12, p. 531-36, December 1934. 
33. Keen, J. A.:

34. Krepusha, S.:

35. Tamarri, M: :
What is the Quickest and Simplest Way of Determining The Causative Organism in Acute Infections of the $E_{a r}$ and Upper Air Passages.

Journal of Laryng. and Otology. Vol.XLIX, No. 10, p. 693 , October 1934.

Primary Tuberculous otitis With Meningitis. Journal of Laryngology and Otology. Vo1. XLIV, No. 7, p. 481, JuIy 1934.

The Mortality of Otitic Intra-cranial Complications. (Mschr. fur Ohrenheilk.) $\mathrm{X}$ and $\mathrm{xi}, 1934$. Abstracted from Journal Laryng and otology Vo1. L, No. 3, p. 220-1, March 1935.

36. Tvermoes, V.:
Frequency of Otitis Media and its Complications. Journal Laryng. and Otology, Vo1. XIIX, No. 12, p. 854, December 1934. 


\section{-BIBLIOGRAFHY-(10)}

37. Rentschler, Henry D.:Otitic Blood Stream Infections, The Guthrie Clinic Bulletin, 4:10 (July 1934).

38. Schlittier, E.: The Treatment of suppurations of the Middle Ear. Schweizer Med. Wschr., 62: 1149. (December 10)1932.

39. Blackwe1l, Hugh B.: The Value of Dry Treatment in Acute Infections of the Ear and Mastoid. The Laryngoscope, 43:390, (May) 1933.

40. Newhart, Horace: Indications for Operative Interference in Middle Ear Supouration. Minnesota Med., 17:438, (August) 1934.

41. Brunner, H.: Suppurations in the Temporal Bone. Wiener Med. Wohnschr., No. 20, 1934. 
42. Costen, James B.: The Management of Ocute Otitis Media and its Complications. Journal of the Missouri State Med. Assoc., 29:118-121 (March)1932.

43. Marcotte, Raymond H.: Clinical Aspects of Acute Otitis Media and Complications, From View point of the General Practitioner. The New England Journal of Med., 203:681685, (October 2) 1930.

44. NeLaggan, J. D.: Treatment of Chronic Suppurative Disease of the Middle Ear.

The British Medical Journal, No. 3732; 9497, (JuIy 16) 1932.

45. Forster, H. V.: Diagnosis and Treatment of Acute Otitis Media, The British Medical Journal, No. 3682: 645-647, (October 10) 1931.

46. Jerkovic, N.: Blood Findings in Suppurative Inflamations 
of the Middle Ear and Their Complications. Otolaryngol. Slav., 3:13, 1931.

47. Turner, A.: Diseases of the Nose, Throat and Ear. Third edition. William Wood and Company, 1932.

48. Gleason, E. B.: Manual of Diseases of Nose, Throat and Ear. Seventh edition. W. B. Saunders Company, 1933.

49. Jackson, Coates: The Nose, Throat and Ear and Their Diseases. W. B. Saunders Company, 1930.

50. Stuart, Lowe, William: Care of the Nose, Throat and Ear. Second edition. London Bailleire, 1929.

51. Greenfield, Samuel D.: Bacteremia of Otitic Origin; Routes of Infection of the Blood Stream. 
-B IBL IOGRAPHY-(13)

Laryngoscope 43:646, 1933.

Abstracted Arch. Otomrhino-laryn., Vol. 20, No. 3, p. 410, September 1934.

Cited by SamueI Kopetziky $\# 1$.

52. Asherson, N.:

Acute Otitis Media in Infancy.

Arch. Dis. Childhood 7:159 (June) 1932.

Abstracted from Arch. Oto-rhino-laryng., No. 18, p. $534,1933$.

53. Liselotte, Meyer: Temperature Curve in Acute Otitis Media

in a Child, Arch. F. Ohren--Nasen-l.

KehIkopfh. 135:77 (May 17) 1933.

Abstracted from Arch. Oto-rhino-laryng. No, 18, 1933.

54. Reiniger, A.:

Puncture of Middle Ear: Diagnostic Significance, Monatschr. F. Ohren. 66:694 (June) 1932.

Abstracted from Arch. Oto-rhino-laryng. No. 17, p. 108-109, 1933. 
55. Love, Andrêw A.: Complications of Otitis Media Without Rupture of Membrane Tympani. Arch. Otomrhinomlaryng. No. 17, p. 297310. (March) 1933.

56. Shapiro, David:

Irrigation of the Ear in Acute Otitis media. Arch. Oto-rhino-laryng. No. 17, p. $384-385,1933$.

57. Beselin, 0.:

Hereditary Dispostion to Otitis Media, Arch. F. Ohren,-Nasen-u. Kehlkopfh. 1932: 335 (September 21,)1932. Abstracted from Arch. Oto-rhino-laryng. No. 17, p. $708,1933$.

58. Meltzer, Philip E.; Gettes, Charles N.: Anatomy and Physiology of the Ear. Arch. Oto-rhinolaryng. No. 18, p. 84-115, 1933.

59. Truffert, P.: 
Cited by Meltzer and Gettes \#58.

60. Kopetzky, Samuel: Acute and Chronic Otitis Media, Sinus Thrombosis, and Petrossal Pyramid Suppuration. Arch. Oto-rhino-laryng. No. 18, p. 344-368, 1933.

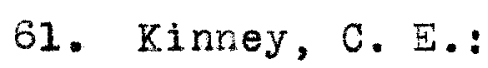

Laryngoscope 42:356, 193\%. Cited by Kopetzky \#60.

62. Okonogi, Shuzo and Shunji, Shusuki: Relation Between Acute Otitis and Nephritis, Otologia 5:295, 1932. Cited by Kopetzky \#60.

63. Lierle, D. M. and Potter, J. J.: Factors Influencing the Course of Mastoiditis in Infancy, Ann. Otol., Rhino., and Laryng. 40:788, 1931.

64. Anderson, Carl M:: Conservative Treatment of Otitis Media, 


\section{-BIBL IOGRAPHY- (16)}

Minnesota Medicine, 16:610 (Octoder) 1933.

65. Voss, 0.:

66. Cone, A. J: :

67. Phillips, W. C.:

68. Wirth, E.:
Statistiches und KIinishes zur Otitis

Media im Kindesalter, Ztschr, F. Laryng., Rhino., Otol., 21:313, 1931.

Cited by Kopetzky \#60.

Incidence of Acute Otitis Media in In-

fants and in Young Children During 19301931.

Arch. Oto-rhino-laryng. 10:797 (Dec.)1931.

Diseases of the Ear, Nose and Throat. Pub. F. A. Davis Co. Philadelphia 1924

Simplest Method of Determining Causal Organism in Acute Otitis Media. Ztschr. F. Laryng. Rhino., Otol. 25:104, 1934.

Abstracted from Ear, Nose and Throat Year Book 1934. 